\title{
Phenomenological interpretation of the shear behavior of reinforced Engineered Cementitious Composite beams
}

Paegle, leva; Fischer, Gregor

Published in:

Cement and Concrete Composites

Link to article, DOI:

10.1016/j.cemconcomp.2016.07.018

Publication date:

2016

Document Version

Peer reviewed version

Link back to DTU Orbit

Citation (APA):

Paegle, I., \& Fischer, G. (2016). Phenomenological interpretation of the shear behavior of reinforced Engineered Cementitious Composite beams. Cement and Concrete Composites, 73, 213-225.

https://doi.org/10.1016/j.cemconcomp.2016.07.018

\section{General rights}

Copyright and moral rights for the publications made accessible in the public portal are retained by the authors and/or other copyright owners and it is a condition of accessing publications that users recognise and abide by the legal requirements associated with these rights.

- Users may download and print one copy of any publication from the public portal for the purpose of private study or research.

- You may not further distribute the material or use it for any profit-making activity or commercial gain

- You may freely distribute the URL identifying the publication in the public portal

If you believe that this document breaches copyright please contact us providing details, and we will remove access to the work immediately and investigate your claim 


\title{
Phenomenological interpretation of the shear behavior of reinforced Engineered Cementitious Composite beams
}

\author{
leva Paegle ${ }^{1}$ and Gregor Fischer ${ }^{2}$ \\ ${ }^{1,2}$ Technical University of Denmark, Department of Civil Engineering, Brovej 118, 2800 Kgs.Lyngby, \\ Denmark
}

Corresponding author: leva Paegle ${ }^{1}$, ievap@byg.dtu.dk, Tel. +45 52650399

${ }^{2}$ gf@byg.dtu.dk

\begin{abstract}
This paper describes an experimental investigation of the shear behavior of beams consisting of steel Reinforced Engineered Cementitious Composites (R/ECC). This study investigates and quantifies the effect of ECC's strain hardening and multiple cracking behavior on the shear capacity of beams loaded in shear. The experimental program consists of R/ECC beams with short $(8 \mathrm{~mm})$ randomly distributed Polyvinyl Alcohol (PVA) fiber and conventional Reinforced Concrete (R/C) counterparts for comparison with varying shear reinforcement arrangements. Beams were loaded until failure while a Digital Image Correlation (DIC) measurement technique was used to measure surface displacements and crack formation. The shear crack mechanisms of R/ECC are described in detail based on findings of DIC measurements and can be characterized by an opening and sliding of the cracks. Multiple micro-cracks developed in a diagonal arrangement between the load and support points due to the strain-hardening response of ECC in tension. The strain-hardening response strongly influenced the shear response of the beam specimen.
\end{abstract}

Keywords: Shear, reinforced ECC. 


\section{INTRODUCTION}

Engineered Cementitious Composites (ECC) is a type of fiber reinforced cementitious material characterized by a multiple cracking and strain hardening response under uni-axial tension (Figure 1). Usually, this behavior is achieved by reinforcing a cementitious matrix with a moderate volume fraction of short, randomly distributed synthetic fibers on the order of $2 \%$ by volume. Depending on the particular composition ECC typically has an ultimate tensile strength between 4 - $6 \mathrm{MPa}$, a first crack strength of $3-5 \mathrm{MPa}$, a tensile strain capacity of $2-5 \%$, a compression strength of $20-90 \mathrm{MPa}$, and Young's modulus of 18 - $34 \mathrm{GPa}[1,2]$. The multiple-cracking behavior of ECC is achieved by micromechanically influencing the interaction between fibers, matrix and their mutual interface. The bridging of cracks and subsequent deformation hardening leads to the formation of multiple cracks with typical crack size ranging from $60-200 \mu \mathrm{m}$ prior to localization of deformations $[1,3]$. The crack width control provided by ECC is desirable from structural and durability viewpoints as it minimizes ingress of water and contained substances which can lead to depassivation and corrosion initiation of steel reinforcement $[4,5]$.

The improved ductility and strength of ECC significantly alters the composite actions of ECC and steel reinforcement compared to traditional reinforced concrete $(R / C)[1,6,7]$. The deformation mechanism of Reinforced ECC (R/ECC) in direct tension differs from R/C. In R/ECC, tensile loads are continually transferred while new cracks form up to a significant tensile pseudo-strain value. In contrast, direct tensile loads in R/C cause a rapid formation and localization of, typically, a single crack. The combination of the ECC and reinforcement materials provides a composite material with compatible deformation characteristics of each constituent. As a result, the damage induced by local slip between reinforcement and matrix is reduced. 


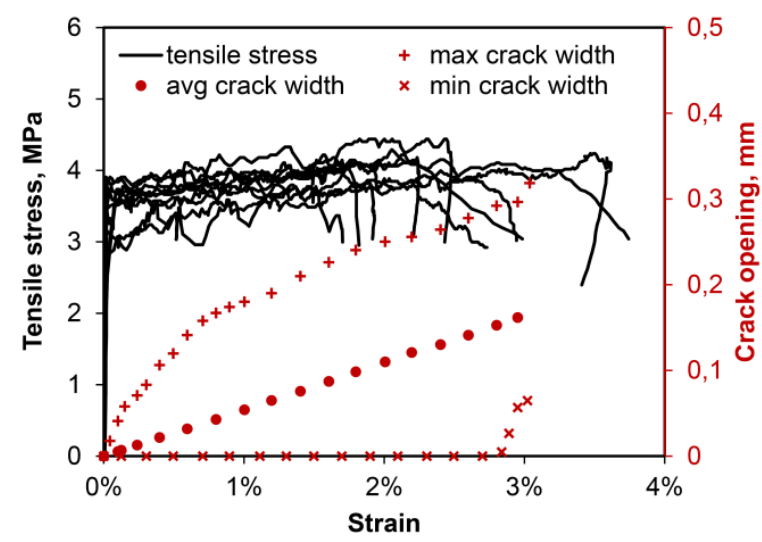

Figure 1. Tensile properties of ECC

\section{REVIEW OF PREVIOUS STUDIES OF THE SHEAR BEHAVIOR OF FIBER REINFORCED CONCRETE}

Particular structural members such as coupling beams, beam ends, short cantilevers, etc. have to resist primarily shear loading. Traditionally in reinforced concrete structures, these members are reinforced with steel shear reinforcement as vertical or inclined discrete stirrups. As shear failure is typically brittle, large safety factors are prescribed for such Reinforced Concrete (R/C) structures. If a more ductile shear failure was possible in R/C structures, lower safety factors could be introduced, reducing the amount of shear reinforcement required for an element. The shear capacity of beams, as predicted by various design codes, vary by a factor of more than 2 [8]. This disparity is due to the lack of a rational, widely accepted theory for calculating the shear strength of $\mathrm{R} / \mathrm{C}$ beams as well as different load and resistance factors. Another common problem associated with shear resistance is related to reinforcement congestion, which may lead to voids and insufficiently compacted concrete resulting in low compressive strength [9]. Therefore, if the shear strength and ductility of concrete as a material could be altered from a brittle to more ductile failure, the demand of traditional stirrups in these elements could be decreased, or potentially eliminated, as safety factors for shear capacity of structure could be reduced. ECC and other Fiber Reinforced Concretes (FRC) may provide such an increased ductility, and for the past decades, the shear behavior of FRC flexural members has been extensively investigated. The addition of fibers has been found to improve the shear resistance and to enhance the shear crack distribution in Reinforced FRC (R/FRC) structures with and without traditional stirrups [9-16]. 
The influence of fibers on concrete shear strength is typically attributed to two main factors: 1) directly by improved stress transfer across the inclined shear crack; and 2) indirectly by controlling crack widths and distribution, allowing increased aggregate interlock and dowel action of longitudinal reinforcement $[10,16]$.

Recently, work has been initiated to include FRC in standard reinforced concrete codes. However, there is currently no broadly used international consensus on addressing these improvements in design codes. For example, the use of deformed steel fibers in place of minimum shear reinforcement was investigated by ACI Subcommittee 318-F, "New Materials, Products, and Ideas" [16]. The study focused on structural beams, where the nominal shear strength attributed to the concrete was not exceeded and therefore minimum transverse reinforcement was required. Based on data from an extensive literature review, the use of deformed steel fibers as an alternative to minimum transverse shear reinforcement was proposed [16] and included initially in ACI 318-08 [17] and has continued in the latest versions of $\mathrm{ACl} 318$ [18]. To ensure adequate material properties of the fiber reinforced concrete, several statements were included in $\mathrm{ACl} 318-08$, including: a) the minimum content of deformed steel fibers should be greater than or equal to $0.75 \%$ by volume; the residual strength obtained from flexural tests in accordance with ASTM C1609 should be b) greater than or equal to $90 \%$ of the measured first-peak strength at mid-span deflection of $1 / 300$ of the span length; c) greater than or equal to $75 \%$ of the measured first-peak strength at mid-span deflection of $1 / 150$ of the span length. By point "b" and "c" ACl-318 suggests using flexural tests to indirectly evaluate the shear behavior of Steel Fiber Reinforced Concrete (SFRC). However, this approach has been questioned. Dinh et. al. $[19,20]$ favor an approach where the residual flexural strength of FRC in beam specimens is assessed at mid span deflections as a function of fiber length and assumes that a single crack forms in FRC beam under four point bending. For materials such as ECC or other FRC with multiple cracking under flexural load this approach is overly conservative.

The Russian design code SP 52-104-2009 [21] provides an alternative where the tensile and compressive strength of FRC are a function of the amount and properties of the fibers and the strength class of the concrete matrix. In this approach an analytical model predicts the shear capacity of beams using empirical formulas. The shear strength of an R/FRC beam is provided by the concrete contribution in the compressive zone and a sum of contributions from stirrups and fibers in the tensile zone. The code allows the use of SFRC without traditional shear reinforcement for beams with a 
height less $150 \mathrm{~mm}$; however, minimum traditional shear reinforcement is needed for beams with a height more than $150 \mathrm{~mm}$ even if SFRC can resist all shear stresses. This approach applies only to particular types of steel fibers.

Similar to ACI 318, the Model code [22] and RILEM TC 162-TDF recommendations [23] specify the use of the residual flexural strength at specific crack openings from flexural beam tests to predict the shear capacity of FRC. The approach proposed by Model code firstly was presented by Minelli in his PhD thesis [24,25]. A further design model also is presented in Model Code in commentary proposed by Foster et al. [26], which is based on Variable Engagement Model (VEM). VEM predicts the behavior of FRC materials through the summation of the two following components: 1) the sum of the behavior of individual fibers (tensile strength) over the cracking plane and 2) the behavior of the concrete matrix.

Japan Society of Civil Engineering (JSCE) provides recommendations for design and construction of high performance fiber reinforced cementitious composites [27] with material properties including multiple fine crack $(<0.2 \mathrm{~mm}$ ) formation and pseudo-strain hardening response (ultimate tensile strain $>0.5 \%)$ under uni-axial tensile loading. The results are highly dependent on tensile strength of the FRC, however, a test method to measure the tensile strength is not provided. Researchers have used factored values of the ultimate strength $[13,28,29]$ or first cracking strength in direct tension [30], or the flexural strength of FRC [31]. A more precise measure of the tensile strength of FRC should be formulated.

Numerous other approaches have been suggested to predict shear capacity $[9,11,12,15,19,29,32-35]$, however, the precision of the results are highly dependent on a specific geometry of the specimen, the fiber type and composite properties of FRC. Although each proposed method predicted the shear strength of a specific beam precisely, the estimate of beams with different geometry, material composition or fiber type are underestimated or overestimated by two to three times $[19,33]$.

\section{RESEARCH SIGNIFICANCE}

The motivation behind the work presented in this paper is to investigate the shear carrying capacity and deformation behavior of structural ECC members with synthetic fibers both in combination with transverse (stirrups) reinforcement and exclusively to provide shear resistance. Compression-shear behavior, which is typical of deep beams having low span to depth $(a / d)$ ratio, is investigated here. The 
main focus of the study is to investigate the shear crack formation and development mechanisms and how they affect the shear capacity. High resolution Digital Image Correlation (DIC) measurements presented in this paper provide valuable insight in the shear crack formation and failure mechanisms, allowing the development of a phenomenological model of the shear failure processes in reinforced concrete and reinforced ECC. Further, as the current design practices for determination of the shear capacity of FRC beams are based on a small number of experiments, this study contributes to the currently available experimental observations of the shear behavior of FRC.

\section{EXPERIMENTAL PROGRAM}

For this study, experimental tests were conducted to examine the shear behavior of ECC beams in terms of the shear capacity and cracking behavior. For comparison, typical concrete specimens with and without transverse reinforcement were also investigated.

\subsection{Materials}

The experimental program consists of Reinforced ECC (R/ECC) beams with $8 \mathrm{~mm}$ long, randomly distributed Polyvinyl Alcohol (PVA) fibers and Reinforced Concrete (R/C) beams. For all R/ECC beams, the same mortar composition was used, consisting of fly ash, cement, water, sand, quartz powder and $2 \%$ by volume of PVA fibers . The properties of fibers are listed in Table 1 . The composition of ECC and concrete beams were different and is presented in Table 2. The concrete mixture used for the reference beams was made with standard components using cement, water and graded aggregates with a maximum size of $16 \mathrm{~mm}$. The concrete was intended to have the similar compressive strength as the ECC used in the companion beam specimens.

Table 1. Properties of PVA fibers

\begin{tabular}{|c|c|c|c|c|c|}
\hline Type & $\varnothing$ & $\mathrm{mm}$ & $\mathrm{MPa}$ & $\mathrm{GPa}$ & $\begin{array}{l}\text { Strain } \\
\text { capacity } \\
\%\end{array}$ \\
\hline PVA & 40 & 8 & 1560 & 40 & 6.5 \\
\hline
\end{tabular}

Table 2. Mixture proportions

\begin{tabular}{|c|c|c|c|}
\hline & $\begin{array}{c}\mathrm{ECC} \\
\mathrm{kg} / \mathrm{m}^{3}\end{array}$ & & $\begin{array}{c}\text { Concrete } \\
\mathrm{kg} / \mathrm{m}^{3}\end{array}$ \\
\hline Cement & 428 & Cement & 372 \\
\hline Fly ash & 856 & Sand $0-4 \mathrm{~mm}$ & 758 \\
\hline Sand & 150 & Aggregate 4-8 mm & 374 \\
\hline
\end{tabular}




\begin{tabular}{lclll}
\hline Quartz powder & 150 & & Aggregate 8-16mm & 756 \\
Water & 321 & & Water & 156 \\
Fibers & $26(2.0 \%)$ & & \\
Superplasticizer & 4.3 & & \\
Cellulose & 0.5 & & & \\
\hline
\end{tabular}

\subsection{Test configuration}

\section{Compression}

Compression tests were conducted on ECC and concrete using cylinders with a diameter of $100 \mathrm{~mm}$ and height of $200 \mathrm{~mm}$. The specimens were loaded to failure in compression with a loading rate of $6.28 \mathrm{kN} / \mathrm{s}$.

\section{Tension}

The tensile stress-strain response of ECC was determined using 'dogbone' specimens with a representative cross section of $25 \mathrm{~mm} \times 50 \mathrm{~mm}$ (Figure 2). A Digital Image Correlation (DIC) measuring technique was used to measure deformations by means of processing images captured of the specimen surface with a previously applied speckle pattern. A description of the photogrammetric data acquisition system is given in section 4.3. For selected specimens, Linear Variable Differential Transformers (LVDTs) were used to verify measurements from the DIC system. Loading of the tensile specimens was performed under cross-head displacement control at a rate of $0.5 \mathrm{~mm} / \mathrm{min}$. 


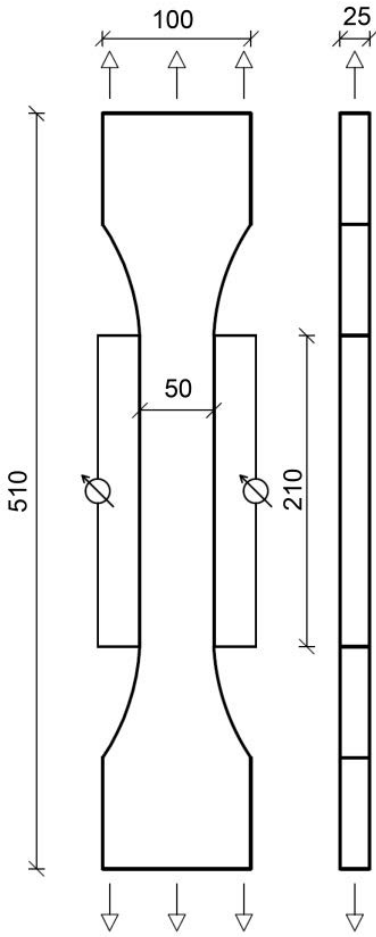

(a)

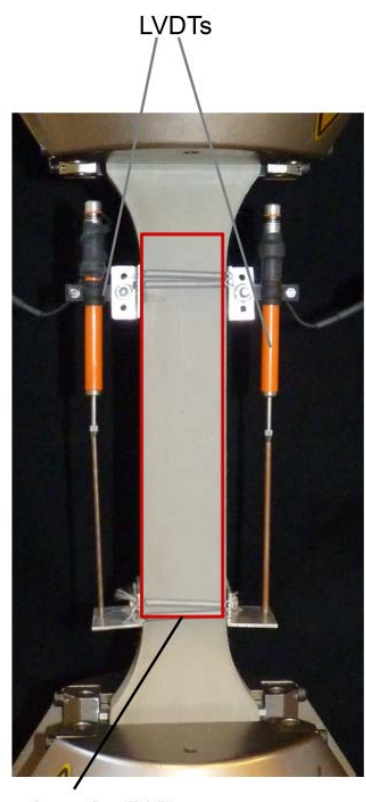

Area for DIC

(b)

Figure 2. Tensile test: (a) specimen geometry; (b) test setup

\section{Shear}

In previous studies, various test setups have been used to determine the behavior of concrete materials in shear. The most frequently used test set-ups are: three and four point bending tests, shear panel tests [36], various modifications of notched specimen tests $[9,37]$ and modifications of the Ohno shear test $[13,38]$. In this study, the load configuration was designed similarly to the Ohno shear beam test to investigate the shear behavior in a realistic situation, while reducing the influence of the moment on inclined crack formation.

The test set-up for the shear beam tests is shown in Figure 3 and Figure 4. The load was applied through a secondary load beam and rollers with a diameter $60 \mathrm{~mm}$. The beams were loaded in a displacement controlled procedure with a loading rate of $0.02 \mathrm{~mm} / \mathrm{s}$ cross-head displacement. The beams were $1100 \mathrm{~mm}$ long, $250 \mathrm{~mm}$ high and with a width of $125 \mathrm{~mm}$. The shear span that was investigated was situated in the middle part of the beam with a length of $300 \mathrm{~mm}$ resulting in a ratio $a / d=212 / 300=1.4$. To eliminate the influence of changing shear crack angle, the geometry of the beams and the test setup was chosen to force shear cracks to form at a $40^{\circ}-45^{\circ}$ angle. 


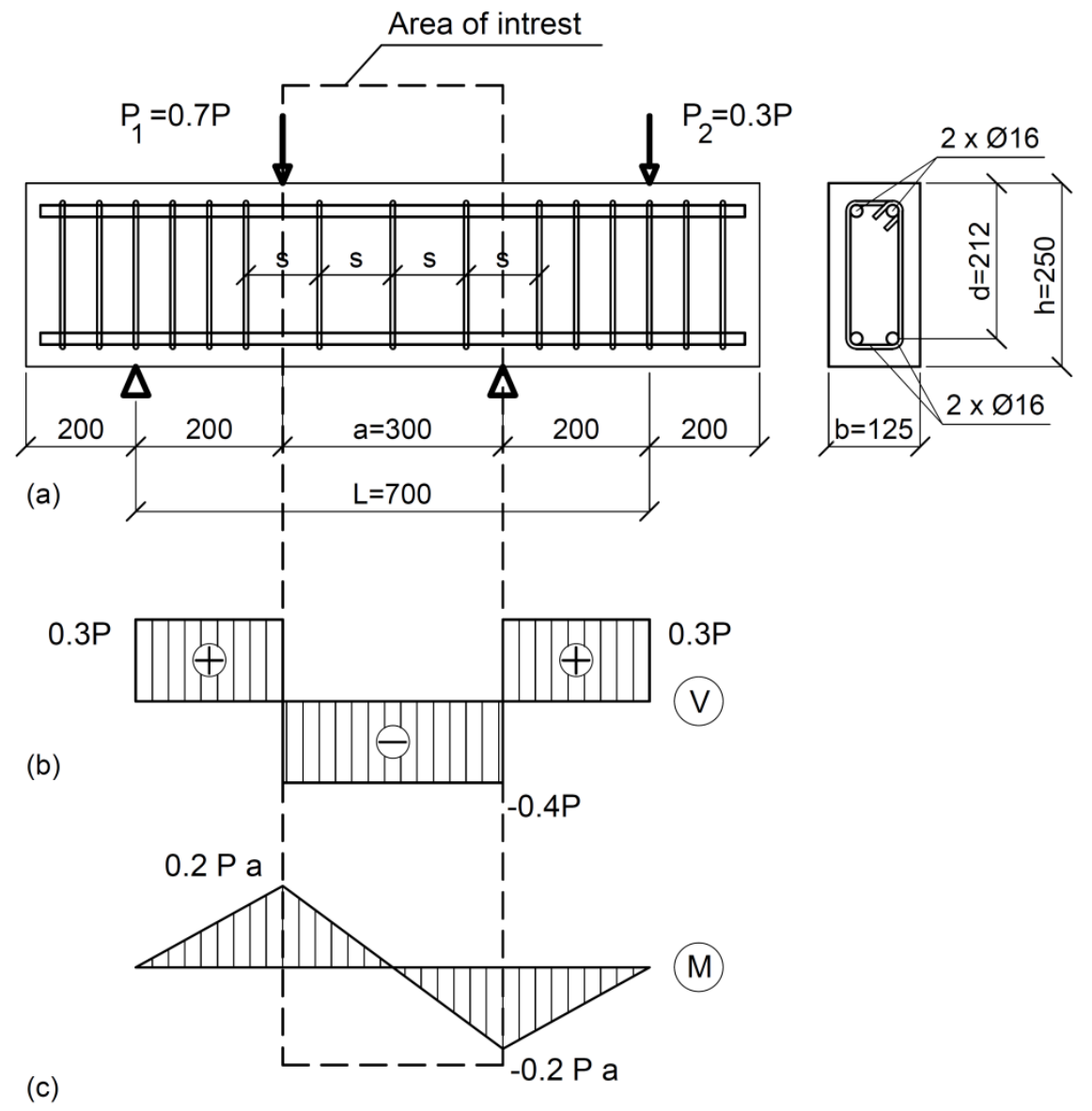

Figure 3. Shear beam test setup configuration (a), shear force distribution (b), moment distribution (c)

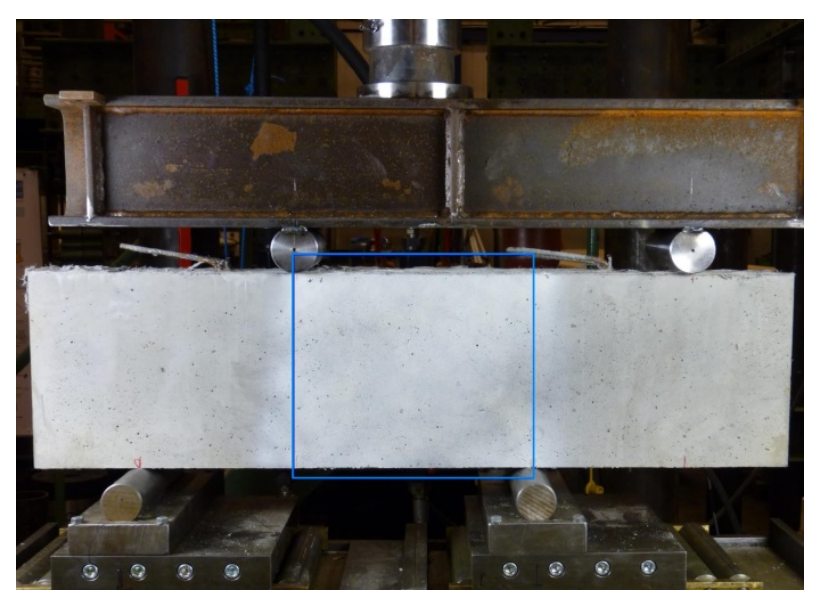

Figure 4. Test set-up and area of interest

All beams were reinforced with four $\varnothing 16 \mathrm{~mm}$ longitudinal reinforcement bars, placed in the corners with $25 \mathrm{~mm}$ cover from adjacent surfaces having a tensile and compressive reinforcement ration of $1.52 \%$. For selected beams, the middle span of the beam was reinforced with $\varnothing 6 \mathrm{~mm}$ transverse 
reinforcement with spacing that varied as function of the effective beam height, $d(d, 1 / 2 d$, and $1 / 4 d)$, as summarized in Table 3 and Figure 4. Additionally, specimens without transverse reinforcement were tested for both R/C and R/ECC. The side spans of the beam were reinforced with $\varnothing 6 \mathrm{~mm}$ transverse reinforcement at $80 \mathrm{~mm}$ spacing to ensure failure would not occur in these regions. Yield strength, $f_{y}$, of the longitudinal and transverse reinforcement was $550 \mathrm{MPa}$.

Table 3. Reinforcement detailing in the test specimens

\begin{tabular}{|c|c|c|c|c|c|c|c|}
\hline \multirow{2}{*}{ Beam } & \multirow{2}{*}{ Material } & \multicolumn{3}{|c|}{$\begin{array}{c}\text { Transverse } \\
\text { reinforcement }\end{array}$} & \multicolumn{3}{|c|}{$\begin{array}{c}\text { Tensile and compressive } \\
\text { reinforcement }\end{array}$} \\
\hline & & $\underset{\mathrm{mm}}{\varnothing}$ & $\begin{array}{l}\text { spacing } \\
\mathrm{mm}\end{array}$ & $\begin{array}{c}\text { ratio } \\
\%\end{array}$ & $\begin{array}{c}\varnothing \\
\mathrm{mm}\end{array}$ & amount & $\begin{array}{c}\text { ratio } \\
\%\end{array}$ \\
\hline $\begin{array}{l}\text { R/ECC-0 } \\
\text { R/C-0 }\end{array}$ & $\begin{array}{l}\text { ECC } \\
\text { RC }\end{array}$ & - & - & 0 & \multirow{5}{*}{16} & \multirow{5}{*}{2} & \multirow{5}{*}{1.52} \\
\hline R/ECC-d & ECC & 6 & 200 & 0,23 & & & \\
\hline $\begin{array}{l}R / C-d \\
R / E C C-1 / 2 d\end{array}$ & ECC & & & & & & \\
\hline $\mathrm{R} / \mathrm{C}-1 / 2 \mathrm{~d}$ & RC & 6 & 100 & 0,45 & & & \\
\hline $\begin{array}{l}R / E C C-1 / 4 d \\
R / C-1 / 4 d\end{array}$ & $\begin{array}{l}\text { ECC } \\
\text { RC }\end{array}$ & 6 & 50 & 0,9 & & & \\
\hline
\end{tabular}

\subsection{Deformation measurements}

A commercial Digital Image Correlation (DIC) system (Aramis, GOM) was used to capture deformations of the front surface of the specimens in the region of interest (Figure 4). The system consists of two black and white 4 mega pixel Charged Couple Device (CCD) cameras and a data acquisition system which captures and processes the images. The two CCD cameras were positioned at the same height and were focused on the same surface, but from different angles, allowing 3D deformation measurements. The images were recorded once per second. In order to facilitate the DIC measurements, adequate contrast in the greyscale of individual objects is required. This was achieved by using black and white spray paint to apply a stochastic speckle pattern. A calibration was preformed prior to testing, using a calibration plate provided by the manufacturer of the DIC system. The photogrammetry system tracks movements of small areas (called facets) of the specimen surface corresponding to 15 by 15 pixel square areas. The system also collects input of loading data from the testing machines such that specific images are easily associated with a recorded load. Additional details on the DIC technique and equipment are available in the literature $[39,40]$. Deformations of selected beams were verified by an arrangement of LVDT's positioned on the back of the specimens. 


\section{Results and discussion}

\subsection{Basic properties}

The typical tensile stress-strain response of ECC is shown in Figure 1. The average first cracking strength in tension for the ECC used in this study was $4.0 \mathrm{MPa}$ and the average ultimate tensile strength was 4.5 MPa. The splitting tensile strength, according to EN 12390-6, was $4.1 \mathrm{MPa}$ for the conventional concrete. The average compressive strength of the ECC and conventional concrete was 53.6 and $51.0 \mathrm{MPa}$, respectively and the average elastic modulus in compression was $16.0 \mathrm{GPa}$ for ECC and 31.6 GPa for concrete.

\subsection{Shear capacity}

\subsubsection{Shear stress-strain relationship}

Figure 5 and Table 4 provide experimental values on the shear behavior of R/C and R/ECC beams.

The experimentally determined ultimate shear load $V_{u}$, ultimate shear stress $\tau_{u}$, and the crack angle $\varphi$ are shown in Table 4. Experimental results are averaged from two identical beam specimens. The equation for calculated shear stress (MPa) was:

$$
\tau_{u}=V_{u} /(b \cdot d),
$$

where $V_{u}$ is the ultimate shear force $(\mathrm{kN}), b$ is the width of the beam $(\mathrm{mm})$ and $d$ is the effective depth (mm). As shown in Table 4, R/ECC provides modest improvements in the shear capacity over R/C beams (maximum 34\% increase) with equivalent amounts of shear reinforcement. For a stirrup spacing of $d$, the shear capacity is $35 \%$ higher than in R/C, however, for other stirrup spacing ECC improves the capacity by $20 \%$ on average. As previously noted, similar compressive and tensile strengths were observed in ECC and concrete. However, the elastic modulus of concrete (31.4 GPa) measured from compressive cylinders was almost 2 times bigger than that of ECC (16.0 GPa) resulting in similar variation in shear stiffness. As a result of the high difference in stiffness between ECC and concrete, the initial shear deformations under constant load level were smaller for R/C than R/ECC (initial slope in curves in Figure 5). However, initiation of a shear cracking in R/C resulted in a rapid increase in shear deformations. Shear crack formation in the R/ECC caused a gradual increase in deformations. The shear deformations at peak load were similar for both the R/ECC and the R/C 
beams without transverse reinforcement and with transverse reinforcement with $d / 2$ and $d / 4$ spacing (Table 4). For the transverse reinforcement with a spacing of $d$, the shear deformations at peak load was 1.25 times higher for the R/ECC beams. The R/ECC beams resisted approximately 1.2 to 1.35 times the shear loads compared to R/C beams (Table 4).

The shear carrying capacity of the reinforced concrete beams without additional transverse reinforcement was $129 \mathrm{kN}\left(\mathrm{V}_{\mathrm{c}}\right)$ (Figure 6). The additional shear carrying capacity of stirrups $\left(\mathrm{V}_{\mathrm{w}}\right)$ can be determinate as the difference between ultimate shear force $\left(V_{u}\right)$ in the beams with transverse reinforcement and the contribution from the concrete $\left(V_{c}\right)$.

$$
V_{w}=V_{u}-V_{c}
$$

The additional contribution of transverse reinforcement in shear carrying capacity is presented in Figure 6. The shear carrying capacity of R/ECC without transverse reinforcement was measured 150 $\mathrm{kN}$.

For FRC, the shear capacity of a member can be considered to be the sum of the contributions from fibers $\left(V_{f}\right)$, the concrete matrix $\left(V_{c}\right)$ and the transverse reinforcement $\left(V_{w}\right)[9,19,27]$. In some cases the contribution of the fibers and the concrete matrix are treated as a combined value $[12,15,35]$. It can be assumed that the contribution from transverse reinforcement is constant for the R/ECC and the R/C beams with the same transverse reinforcement spacing. Thus, the ultimate shear force in the R/ECC beam should be a sum of contribution of shear carrying capacity by ECC $\left(\mathrm{V}_{\mathrm{ECC}}\right)$ and the additional contribution of transverse reinforcement $\left(\mathrm{V}_{\mathrm{w}}\right)$. However, Figure 6 illustrates that there is an additional contribution in ultimate shear load by R/ECC between $15 \mathrm{kN}$ and $24 \mathrm{kN}$. This additional contribution may be due to improved composite action of R/ECC. 


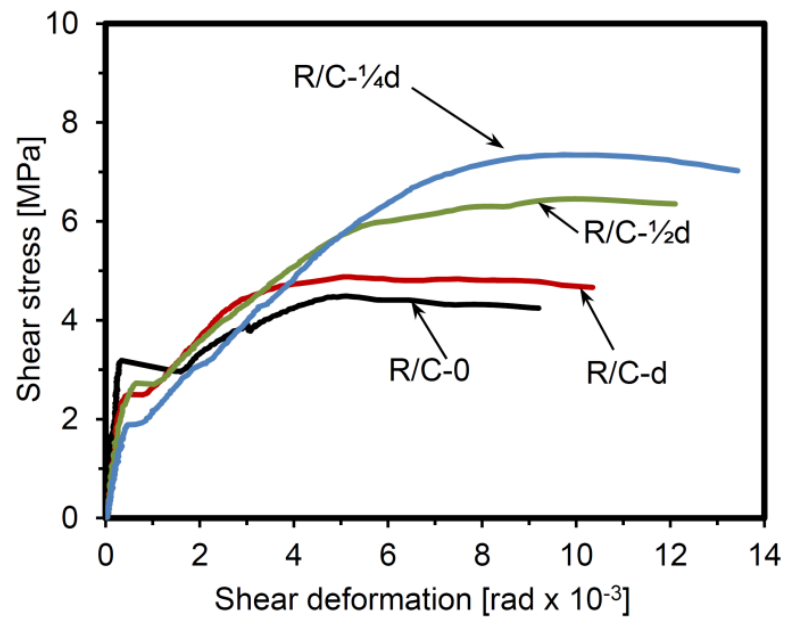

(a)

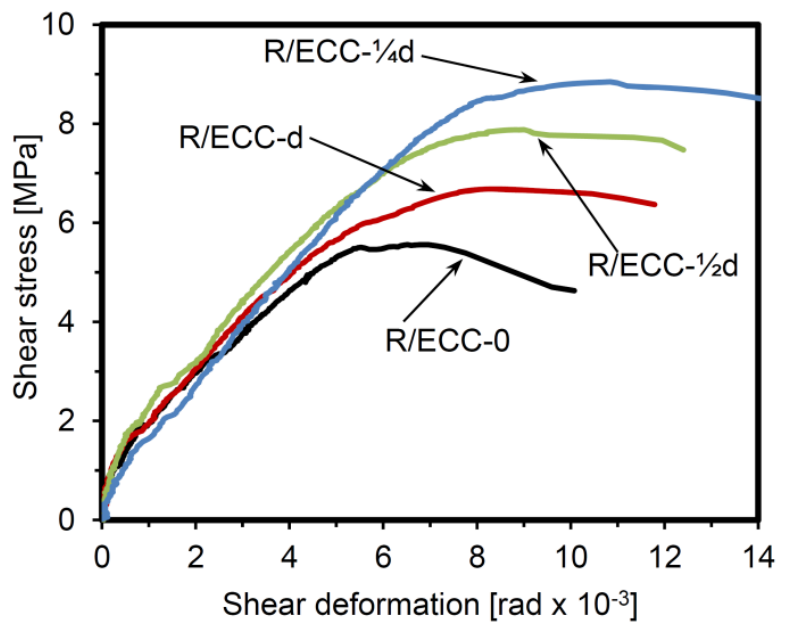

(b)

Figure 5. Shear stress - strain relationship for (a) R/C and (b) R/ECC. Deformations captured using DIC.

Table 4. Test results from shear beam tests

\begin{tabular}{|c|c|c|c|c|c|c|}
\hline & $\begin{array}{c}\text { Peak } \\
\text { shear } \\
\text { force, } V_{u} \\
{[\mathrm{kN}]}\end{array}$ & $\begin{array}{c}\text { Peak } \\
\text { shear } \\
\text { stress, } \tau_{u} \\
{[\mathrm{MPa}]}\end{array}$ & $\begin{array}{c}\text { Shear } \\
\text { strain at } \\
\text { peak, } \varepsilon^{-3} \\
{\left[\mathrm{rad} \times 10^{-3}\right]}\end{array}$ & $\begin{array}{c}\text { Shear } \\
\text { crack } \\
\text { angle, } \varphi \\
\text { [deg] }\end{array}$ & $\tau_{\mathrm{uECC}} / \tau_{\mathrm{u}}$ & Eu ECC / \&u RC \\
\hline R/ECC-0 & 150 & 5.7 & 6.65 & 42.5 & \multirow{2}{*}{1.19} & \multirow{2}{*}{1.07} \\
\hline $\mathrm{R} / \mathrm{C}-0$ & 129 & 4.8 & 6.20 & 42.5 & & \\
\hline R/ECC-d & 179 & 6.7 & 7.77 & 42.5 & \multirow{2}{*}{1.34} & \multirow{2}{*}{1.24} \\
\hline$R / C-d$ & 134 & 5.0 & 6.26 & 44.0 & & \\
\hline $\mathrm{R} / \mathrm{ECC}-1 / 2 \mathrm{~d}$ & 200 & 7.5 & 8.36 & 43.5 & \multirow{2}{*}{1.21} & \multirow{2}{*}{0.98} \\
\hline $\mathrm{R} / \mathrm{C}-1 / 2 \mathrm{~d}$ & 164 & 6.2 & 8.51 & 43.0 & & \\
\hline $\mathrm{R} / \mathrm{ECC}-1 / 4 \mathrm{~d}$ & 234 & 8.8 & 10.84 & 42.5 & \multirow{2}{*}{1.20} & \multirow{2}{*}{1.07} \\
\hline $\mathrm{R} / \mathrm{C}-1 / 4 \mathrm{~d}$ & 193 & 7.3 & 10.05 & 43.5 & & \\
\hline
\end{tabular}




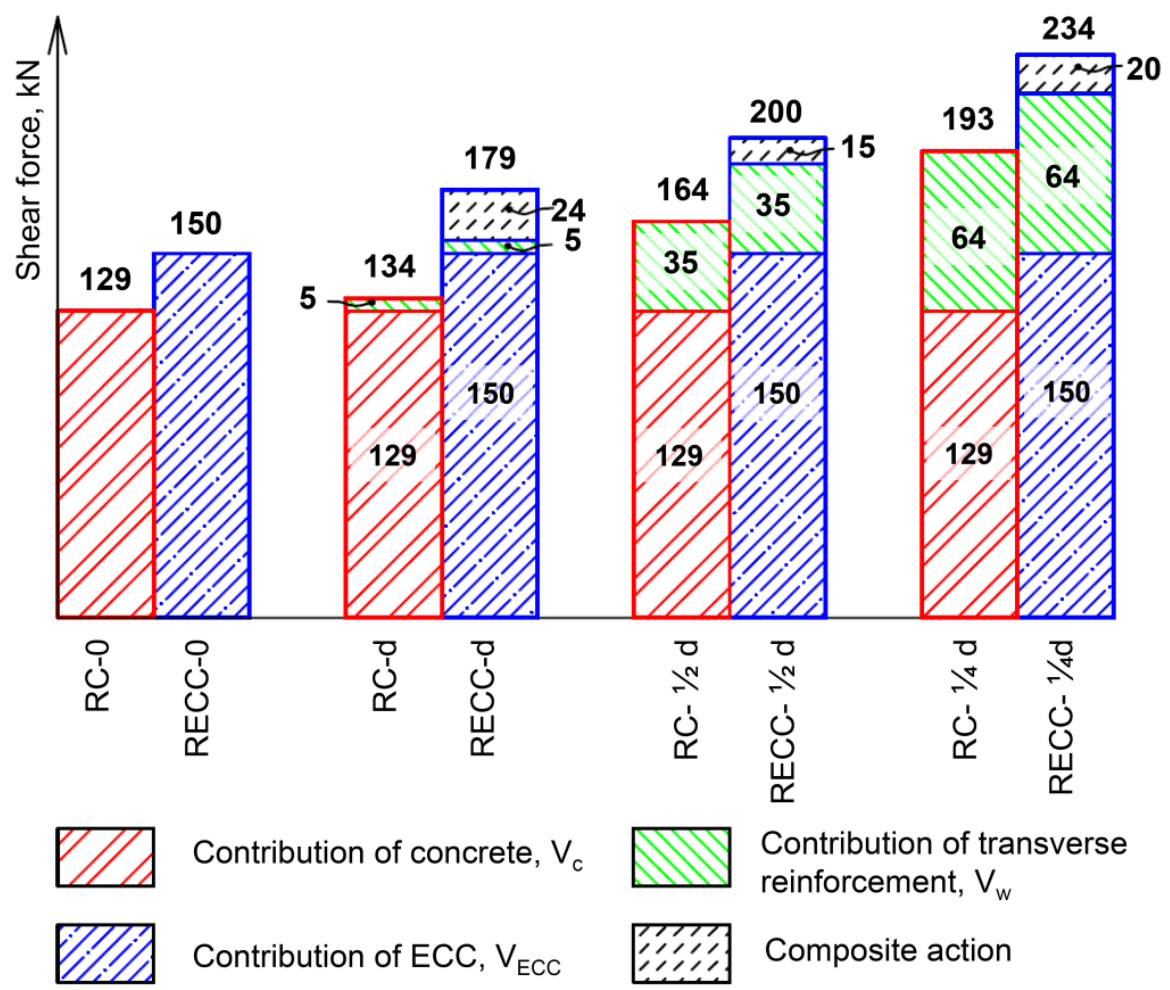

Figure 6. Contribution of concrete/ECC, transverse reinforcement and composite action on shear capacity

\subsubsection{Shear crack deformations}

Previous investigations on the shear behavior of R/ECC beams have not reported details on the crack formation process, which can be described as a combined crack opening and sliding. As shown in Figure 7 , the total crack deformation, $u$, consists of crack opening, or perpendicular separation between crack surfaces, and crack sliding, or parallel translation of crack surfaces. Using DIC, deformations are measured by selecting two virtual markers on the images of the specimen with marker on each side of the crack (Figure 7). Subsequently, the relative displacements between the two markers were obtained using standard DIC techniques. Initially the line between these two markers is set to be perpendicular to the predicted crack surface as illustrated in Figure 7 . The crack opening and sliding values (for R/ECC values taken as the average value of at least six visible cracks) at 4.5 MPa and peak load are shown in Table 5. Additional measurements are presented in Figure 8, as discussed in a later section. 
The comparison of measured crack deformations (opening and sliding) at a shear stress of $4.5 \mathrm{MPa}$ and peak show that individual crack widths measured in R/ECC are significantly smaller than those in R/C under similar applied shear stresses, regardless of transverse reinforcement configuration. Shear reinforcement in R/C increases the shear resistance directly through the tensile capacity of stirrups and indirectly by improved aggregate interlock as shear reinforcement controls crack widths. For the same shear stress level, an addition of $0.9 \%$ of traditional shear reinforcement (no stirrups vs stirrups with spacing $s=1 / 4 \mathrm{~d}$ ) reduced crack sizes by $20 \%$ to $25 \%$ (see Table 5 ). In R/ECC, the use of transverse reinforcement reduced the crack sizes by approximately $50 \%$ at a stirrup spacing of $s=1 / 4 \mathrm{~d}$. The total number of shear cracks detected by the DIC system and the combined sliding and opening (i.e., measured across all cracks) in the R/C and the R/ECC beams are presented in Table 5. Experimental results indicate that ECC's contribution to the shear capacity is similar to that of steel shear reinforcement. Fibers in the cementitious matrix control shear crack widths and improve crack distribution. For example, only one shear crack was detected for the R/C beam without transverse reinforcement while eight to nine cracks were detected in the corresponding R/ECC beams. The R/C beams with transverse reinforcement with $\mathrm{d} / 4$ spacing had $4-5$ cracks at ultimate load, while the similarly reinforced R/ECC beams had 15-16 cracks. Additionally, fibers in ECC improved shear resistance by bridging cracks and transferring stresses over the crack. Individual crack deformations at peak load for the individual materials are similar regardless of the amount of transverse reinforcement; however, for R/ECC the crack deformations (opening and sliding) at failure were $20 \%$ to $25 \%$ of the crack size in R/C (Table 5). This indicates the potential benefits of R/ECC in structures exposed to moisture and other aggressive substances.

The sum of all crack openings at the ultimate loads increase by adding more transverse reinforcement. This is due to the fact that the individual crack openings are similar at ultimate stage independent of the amount of transverse reinforcement. Therefore, as the number of cracks in beams with more reinforcement increases, the total deformations increase. The experimental results indicate that additional shear reinforcement reduces the sliding of shear region for both materials at a stress level of 4.5 MPa. The sliding of shear cracks is highly dependent on opening of a single crack for R/C as aggregate interlock restricts sliding. The contributions from fibers and traditional reinforcement reduce the sliding of shear crack until ultimate loading. 


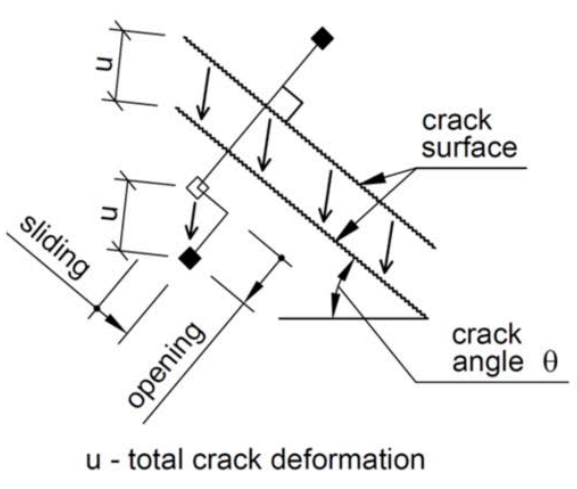

(a)

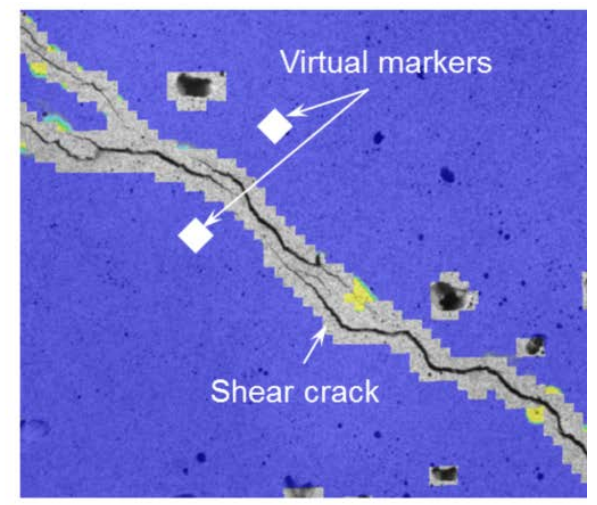

(b)

Figure 7. Illustration of crack deformations: (a) schematic definition of crack opening and sliding; (b) illustration from DIC software

Table 5. Values of crack opening and sliding

\begin{tabular}{|c|c|c|c|c|c|}
\hline \multicolumn{6}{|c|}{ Shear stress - 4.5 MPa } \\
\hline & \multicolumn{2}{|c|}{$\begin{array}{l}\text { Values of individual } \\
\text { shear cracks }\end{array}$} & \multicolumn{3}{|c|}{ Values of all shear cracks } \\
\hline & Opening & Sliding & \multirow{2}{*}{$\begin{array}{c}\text { \# of } \\
\text { cracks }\end{array}$} & \multirow{2}{*}{$\frac{\text { Opening }}{\mathrm{mm}}$} & \multirow{2}{*}{$\frac{\text { Sliding }}{\mathrm{mm}}$} \\
\hline & $\mathrm{mm}$ & $\mathrm{mm}$ & & & \\
\hline $\mathrm{R} / \mathrm{C}-0$ & 1.00 & 0.30 & 1 & 1.00 & 0.30 \\
\hline R/C-d & 0.75 & 0.20 & $1-2$ & 0.78 & 0.20 \\
\hline $\mathrm{R} / \mathrm{C}-1 / 2 \mathrm{~d}$ & 0.50 & 0.15 & 3 & 0.64 & 0.15 \\
\hline $\mathrm{R} / \mathrm{C}-1 / 4 \mathrm{~d}$ & $0.20-0.30$ & 0.05 & 4 & 0.55 & 0.14 \\
\hline R/ECC-O & 0.15 & 0.05 & $5-9$ & 0.61 & 0.11 \\
\hline R/ECC-d & 0.10 & $<0.05$ & $6-10$ & 0.60 & 0.17 \\
\hline R/ECC- $1 / 2 d$ & 0.10 & $<0.05$ & $8-9$ & 0.50 & 0.14 \\
\hline $\mathrm{R} / \mathrm{ECC}-1 / 4 \mathrm{~d}$ & $<0.10$ & 0 & $9-10$ & 0.50 & 0.14 \\
\hline \multicolumn{6}{|c|}{ Peak shear stress } \\
\hline & \multicolumn{2}{|c|}{$\begin{array}{l}\text { Values of individual } \\
\text { shear cracks }\end{array}$} & \multicolumn{3}{|c|}{ Values of all shear cracks } \\
\hline & Opening & Sliding & \# of & Opening & Sliding \\
\hline & $\mathrm{mm}$ & $\mathrm{mm}$ & cracks & $\mathrm{mm}$ & $\mathrm{mm}$ \\
\hline $\mathrm{R} / \mathrm{C}-0$ & \multirow{4}{*}{$1.10-1.40$} & \multirow{4}{*}{$0.40-0.90$} & 1 & 1.36 & 0.46 \\
\hline $\mathrm{R} / \mathrm{C}-\mathrm{d}$ & & & $1-2$ & 1.59 & 0.66 \\
\hline $\mathrm{R} / \mathrm{C}-1 / 2 \mathrm{~d}$ & & & 4 & 1.70 & 0.58 \\
\hline $\mathrm{R} / \mathrm{C}-1 / 4 \mathrm{~d}$ & & & $4-5$ & 1.95 & 0.70 \\
\hline R/ECC-O & \multirow{4}{*}{$0.25-0.35$} & \multirow{4}{*}{$0.05-0.20$} & $8-10$ & 1.39 & 0.48 \\
\hline R/ECC-d & & & $9-12$ & 1.49 & 0.38 \\
\hline R/ECC- $1 / 2 d$ & & & $11-14$ & 1.61 & 0.30 \\
\hline R/ECC- $1 / 4 \mathrm{~d}$ & & & $15-16$ & 2.06 & 0.24 \\
\hline
\end{tabular}

\subsubsection{Formation of shear cracks}

Figure 8 and Figure 9 show the calculated strain spectrum from DIC measurements overlaid on an image of the specimen surface. The DIC system provides a useful illustration of the cracking behavior 
by overlaying a color-contour of facet strains on an image of the deformed specimen. Light colors indicate high facet strains (indicating cracking has occurred in either concrete or ECC), while the dark color indicates low facet strains. Although strain does not accurately represent crack formation, the images indicate cracks with regions of very high strains. The blank areas in the color contour overlay are caused by unrecognizable facets either by excessive deformations or by entrapped air pores on the specimen surface [40].

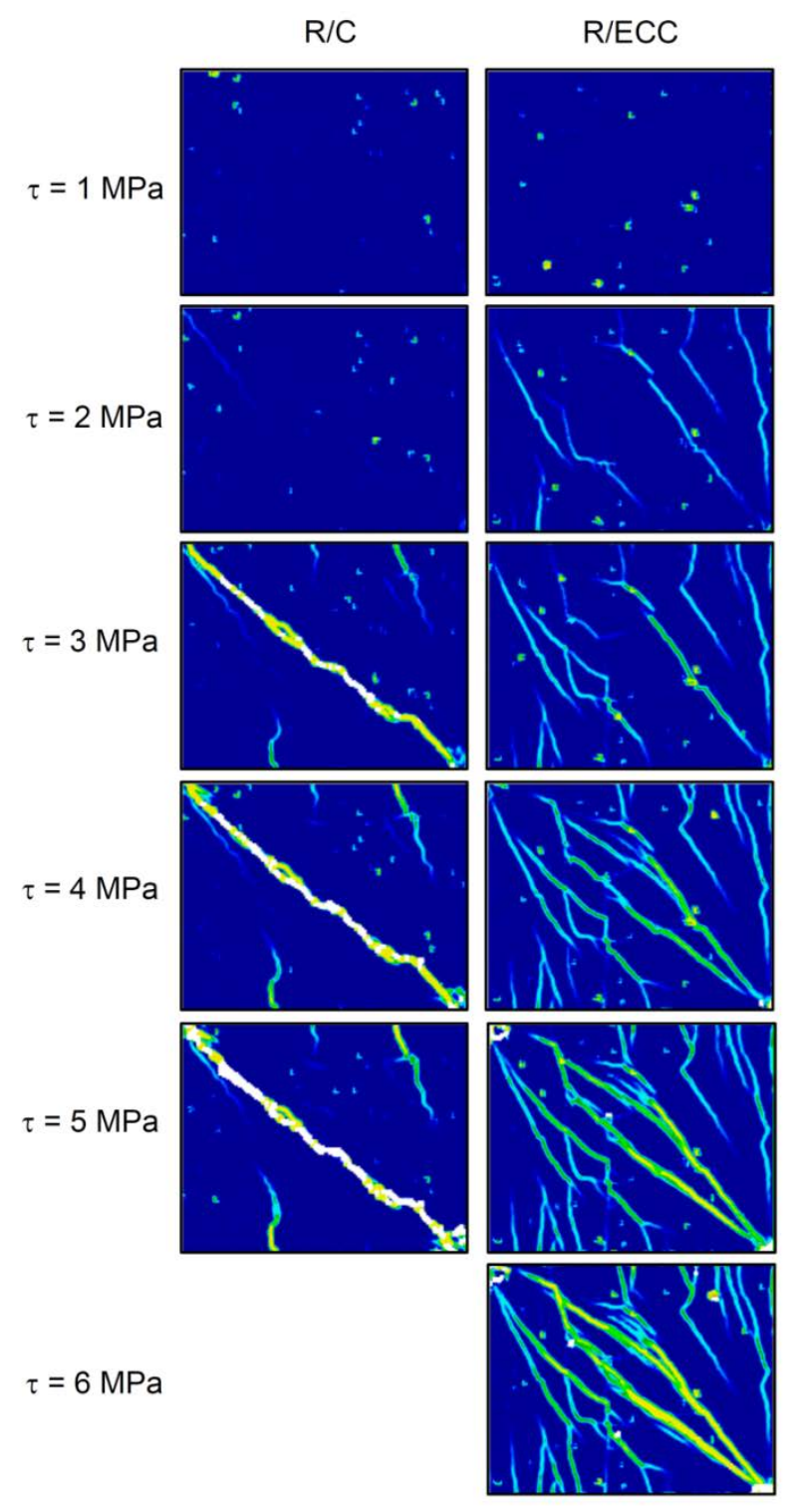

Figure 8. Crack formation in a) R/C and b) R/ECC beam specimens at different load stages

Figure 8 illustrates the development of cracks at varying load levels in R/C (left column) and R/ECC (right column) beam specimens with stirrup distance $s=d(R / C-d$ and R/ECC-d). As can be seen, the 
main shear cracks develop directly along the diagonal between load and support and in some cases a shear-compression failure was clearly noticed. Additional cracks parallel to this diagonal form in R/ECC. For R/C the first visible cracks appear at a shear stress of approximately $\tau=2 \mathrm{MPa}$, which corresponds to $40 \%$ of peak shear stress. Before the shear stress reaches $\tau=3 \mathrm{MPa}$, the shear crack is visible between load and support points. The majority of cracks forms before the loading reaches $\tau=3 \mathrm{MPa}$. Additional load causes crack openings to increase, but additional cracks are typically not introduced in R/C.

In the R/ECC-d beam (Figure 8, right column) a different cracking behavior was observed. The first diagonal shear cracks appear in the R/ECC-d beam at a shear stress of approximately $\tau=1.5 \mathrm{MPa}$ with secondary parallel cracks initiating in close proximity and short sequence. At $\tau=2 \mathrm{MPa}$ the first flexural cracks appear in the regions where the flexural moment in the shear span is the largest. Flexural cracks, which initially form vertically, propagate at an inclination due to shear forces in the beam. Shear cracks continue to develop further into the beam at shear stress of $\tau=3 \mathrm{MPa}$ which corresponds to $45 \%$ of the peak shear strength. The cracks propagate at an angle of approximately $43^{\circ}$ between the load points. Some of the cracks (indicated in light color) seen in the images are several micro cracks, which cannot be differentiated due to limited resolutions of the images. Increased micro cracking occurs parallel to the first developed shear crack band in image which corresponds to shear stress of $\tau=5 \mathrm{MPa}$. More flexural cracks develop further into the beam and the widths of all cracks increase. The subsequent ultimate failure occurred in a localized fracture plane parallel to the first developed shear crack as the two beam parts are separated perpendicular to the fracture plane. 

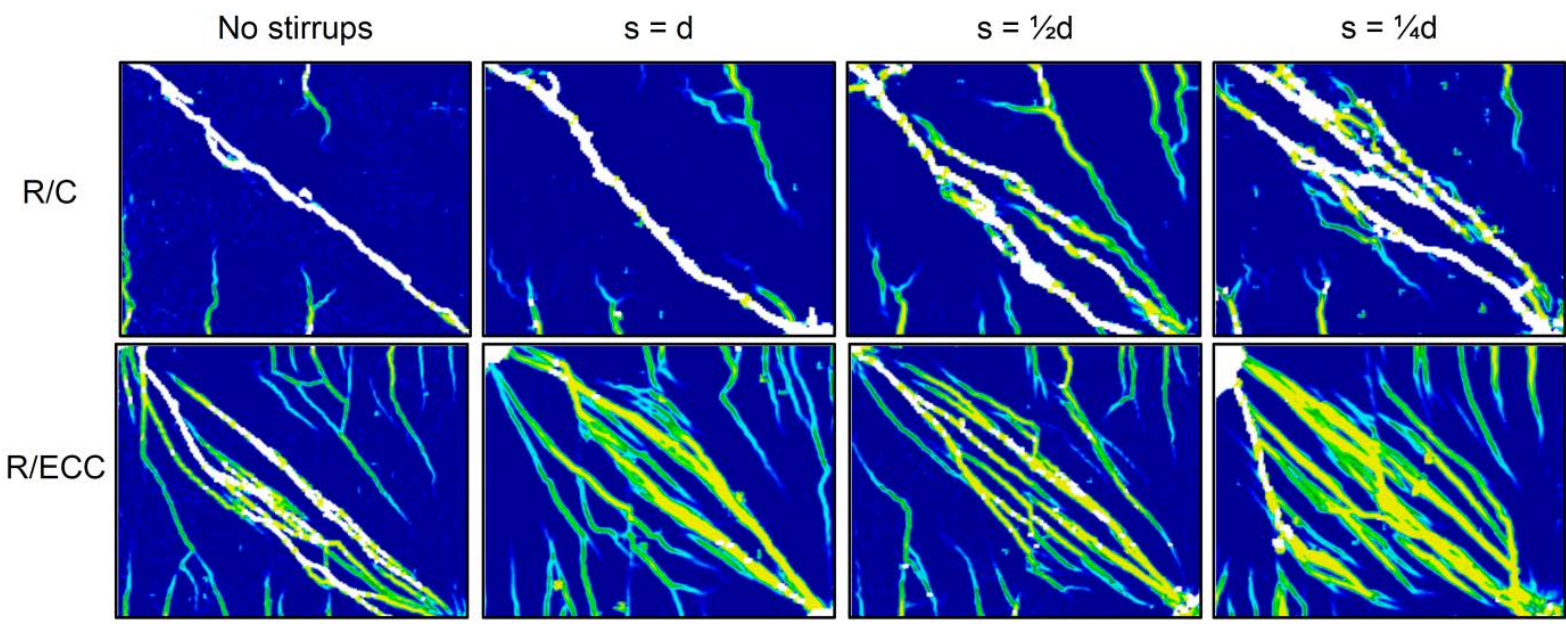

Figure 9. Crack distribution of a) R/C and b) R/ECC beams at $100 \%$ of peak strength for increasing amounts of shear reinforcement (decreasing spacing)

Figure 9 shows the crack patterns at peak load for R/C and R/ECC beams with varying amounts of stirrups. All beams demonstrated failure due to shear loading. Similar to the behavior in uni-axial tension, R/ECC beams exhibited multiple cracking under shear loading prior to localization and failure. Results clearly show that increasing traditional shear reinforcement in R/C and R/ECC beams led to formation of more cracking prior to failure. Figure 10 and Figure 11 illustrate a significant difference in crack distributions from R/C and R/ECC beams. Cracking in R/ECC beams consisted of a large number of fine cracks, while R/C beams tended to have a small number of wider cracks. The total deformations induced by cracking were similar in R/C and R/ECC beams, however individual crack openings were minimized in R/ECC beams.

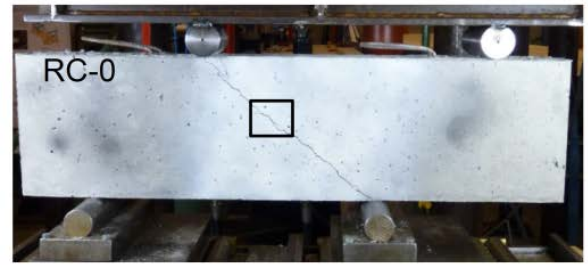

(a)

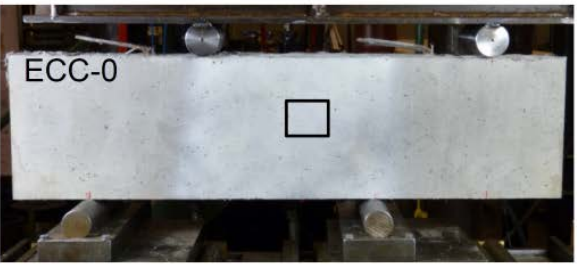

(b)

Figure 10. Shear cracks in beam at peak shear stress: a) R/C and b) R/ECC 


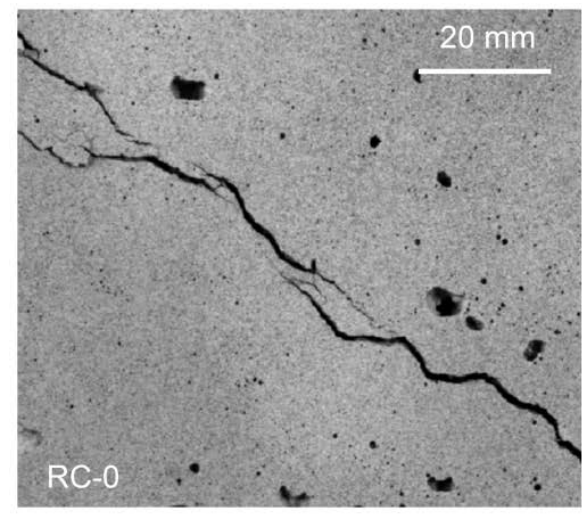

(a)

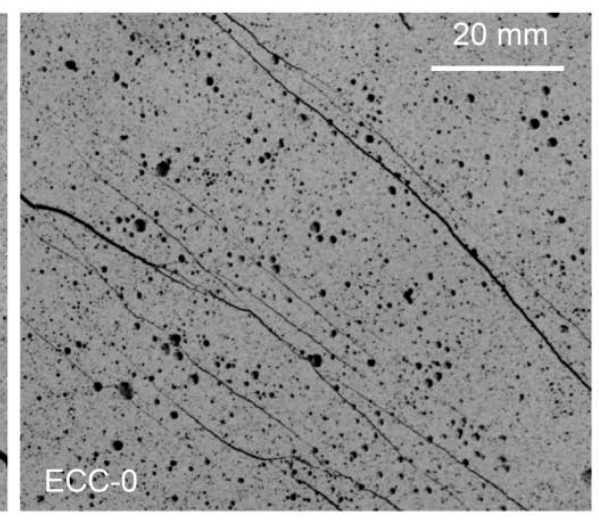

(b)

Figure 11. Zoom in highlighted region in Figure 10: a) R/C and b) R/ECC

\subsubsection{Shear crack development}

The investigation of shear crack formation and propagation is important to improve the current understanding of the shear behavior of structures. The intention is to develop more precise predictions of the shear capacity and to increase understanding of shear cracking behavior, which may lead to the development and design of materials with increased shear resistance and deformation capacity.

Figure 12 shows the observed crack opening and sliding responses for R/C and R/ECC specimens with and without conventional transverse reinforcement obtained by DIC. First cracking strengths were similar for R/C and R/ECC, although in most cases it was $~ 10-30 \%$ higher for R/C. However, the initial (immediate) crack opening was on average 10 times larger for R/C beams. The initial crack opening for R/C reduced by addition of stirrups, while stirrups had only minimal impact on initial crack opening for R/ECC. Crack opening occurs prior to crack sliding in R/ECC, while crack sliding occurs simultaneously with crack opening in R/C. Crack sliding initiated in R/ECC after crack openings of roughly $0.1 \mathrm{~mm}$, which is approximately $1 / 2$ the maximum particle size contained in the R/ECC material. Crack sliding and opening in the R/ECC beams occurred at an increased rate once crack widths exceeded approximately $0.20-0.25 \mathrm{~mm}$. With additional crack opening, the majority of PVA fibers in the ECC ruptured, leading to shear failure. Optimization of the composite action between fibers and cementitious matrix could lead to a fiber pullout failure which would provide further increase in ductility prior the ultimate failure. 


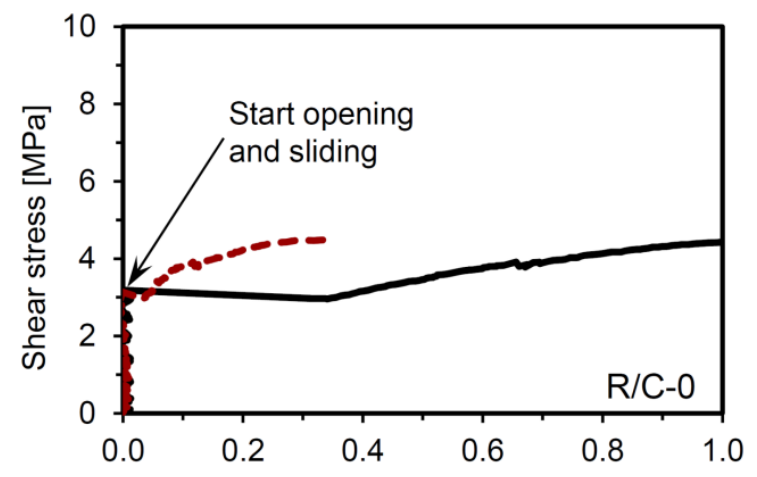

(a) Crack opening and sliding [mm]

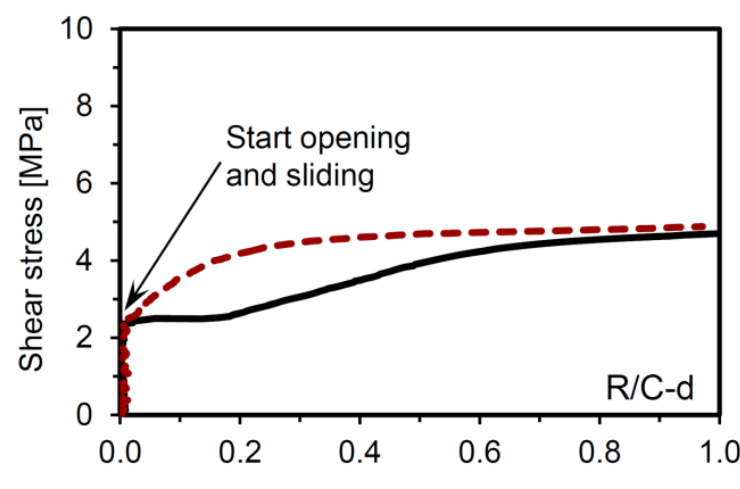

(c) Crack opening and sliding [mm]

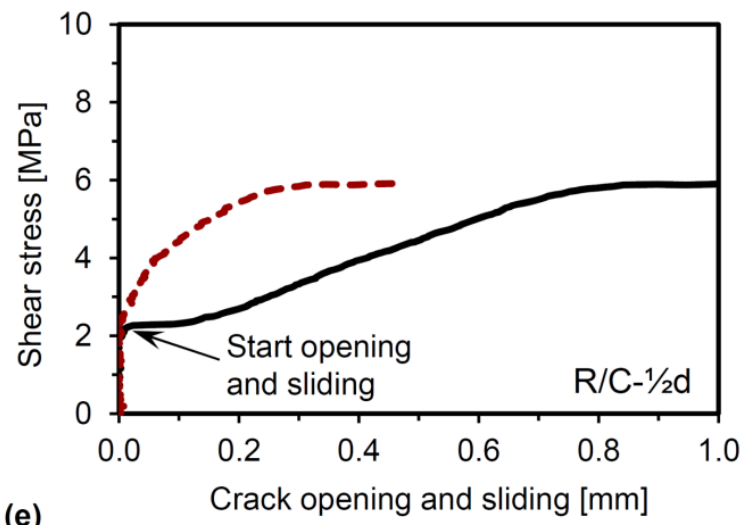

(e)

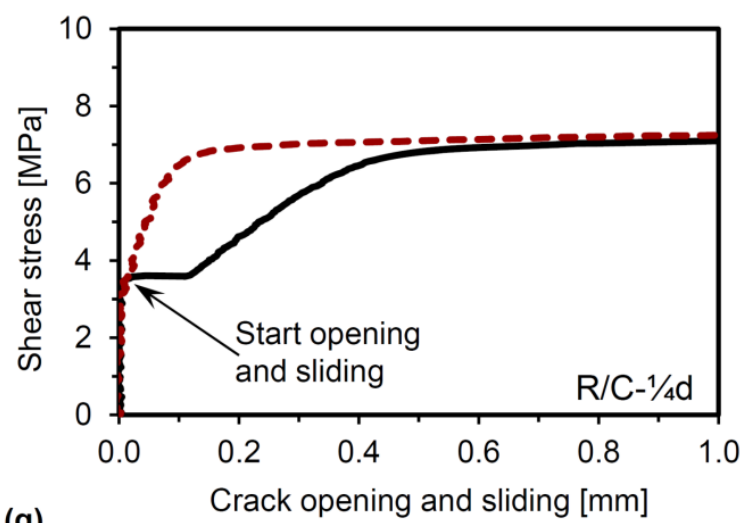

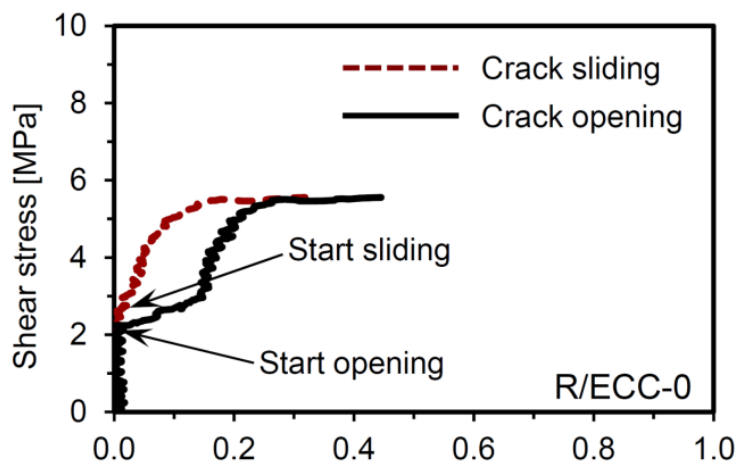

(b) Crack opening and sliding [mm]
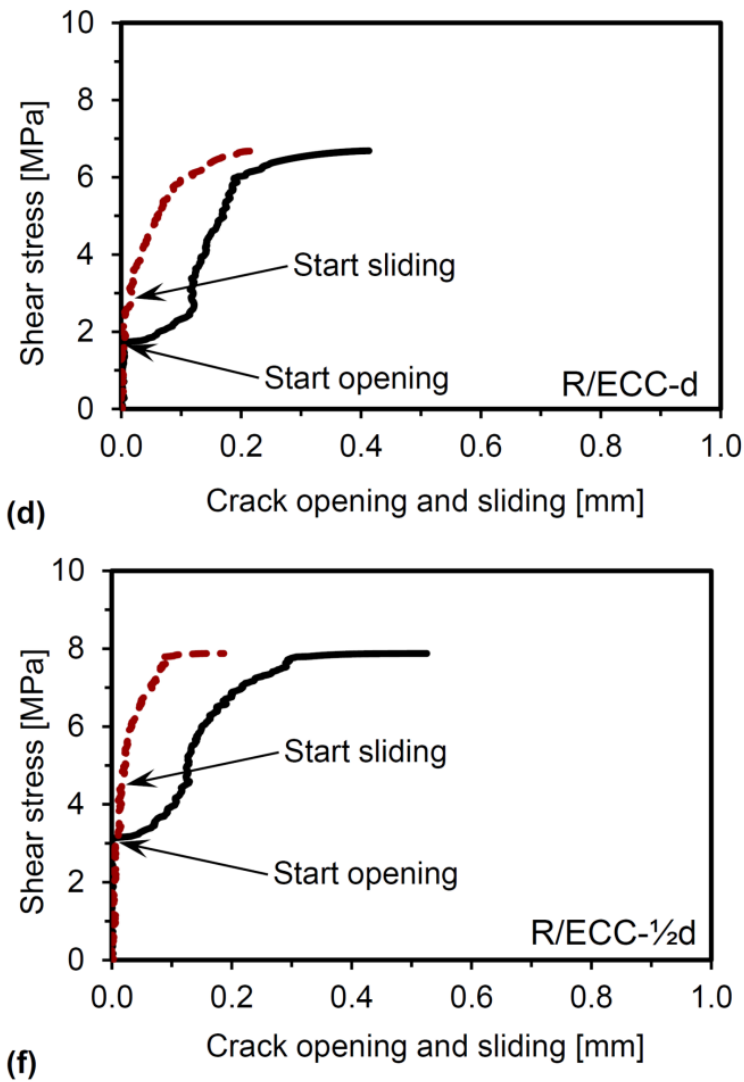

(f)

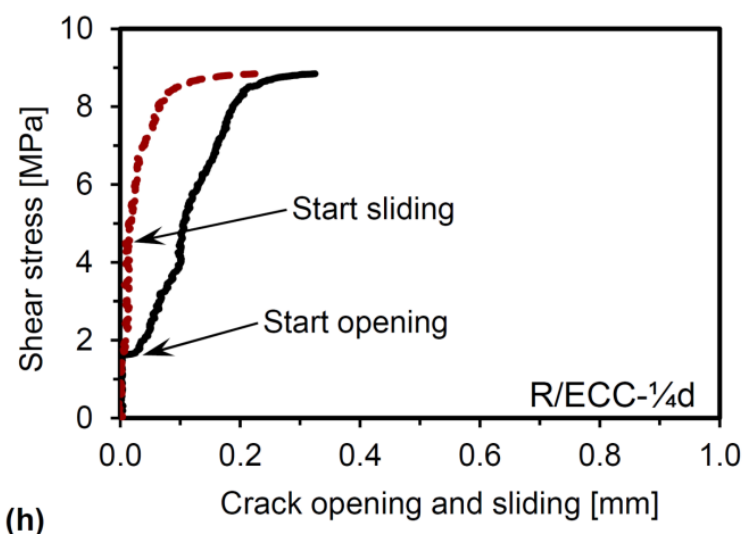

Figure 12. Characteristic shear stress - crack opening and sliding deformation relationship for: (a) R/C0; (b) R/ECC-0; (c) R/C-d; (d) R/ECC-d; (e) R/C-1/2d; (f) R/ECC-1/2d; (g) R/C-1/4d and (h) R/ECC-1/4d beams 


\section{Phenomenological model of shear crack development}

To explain the mechanisms controlling shear cracking and failure in both R/C and R/ECC, a phenomenological model has been developed and is illustrated in Figure 13 based on the results shown in Figure 12. In R/C before cracking, stirrup and concrete strains are equal. As concrete cracks at small strains, significant loading of shear reinforcement only occurs after inclined shear cracks form in the concrete. Thus, stirrup spacing does not influence the initial cracking strength. Figure 13 (b) and (c) illustrate the shear crack development mechanism for reinforced concrete (R/C) consisting of four stages:

1. Crack formation - brittle fracture occurs, resulting in crack opening and relatively small crack sliding without increasing load. For concrete without transverse reinforcement, approximately $30 \%$ of the ultimate crack opening occurs in stage 1 ; by adding transverse reinforcement, the immediate crack opening at first shear crack formation is reduced.

2. Crack opening and sliding increase with additional load resisted by activation of aggregate interlock and stirrups bridging the crack. The amount of crack sliding is highly dependent on aggregate interlock which is highly dependent on aggregate size. The effect of aggregate interlock is reduced with additional crack deformations as fewer aggregates participate, thus, the stress in the stirrups increases. Specimens without transverse reinforcement transfer shear stresses across the crack by aggregate interlock additionally to the dowel effect of the longitudinal reinforcement. Due to reduced aggregate interlock and lack of stirrups, the crack opens and slides more rapidly. Reduced aggregate interlock results in significant crack sliding. For smaller transverse reinforcement spacing, multiple cracking can occur at this stage.

3. Stage 3 starts when the transverse reinforcement starts to yield and aggregate interlock becomes insignificant due to increased crack openings. This stage is delayed through the addition of larger amounts of traditional reinforcement in the element, due to improved control of crack sizes. Shear stresses are mainly transferred across the crack by stirrups. Crack opening and sliding occurs very rapidly and without significantly increased applied load.

4. Failure - specimen failure is caused by rupture of the stirrups. 

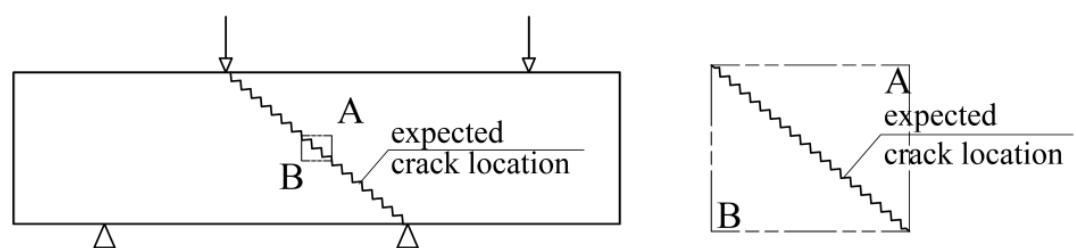

(a)

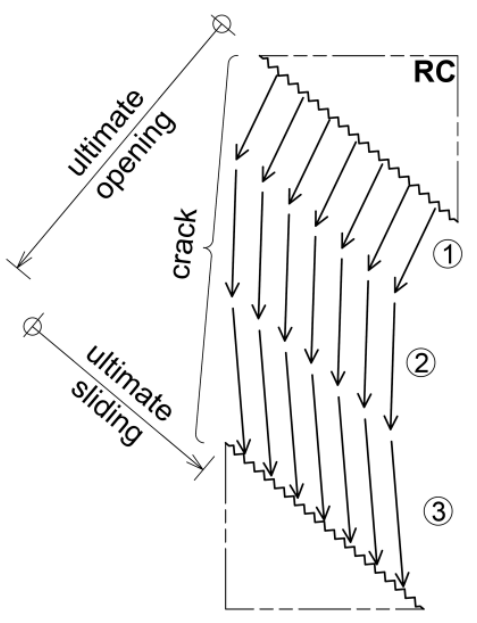

(b)

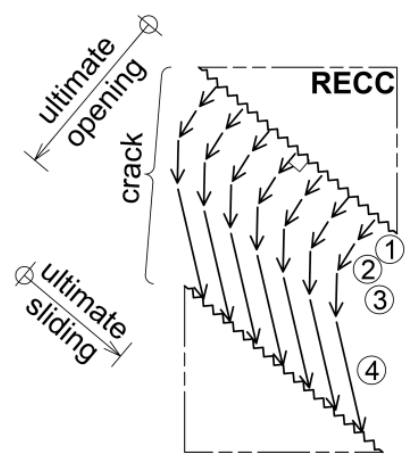

(d)
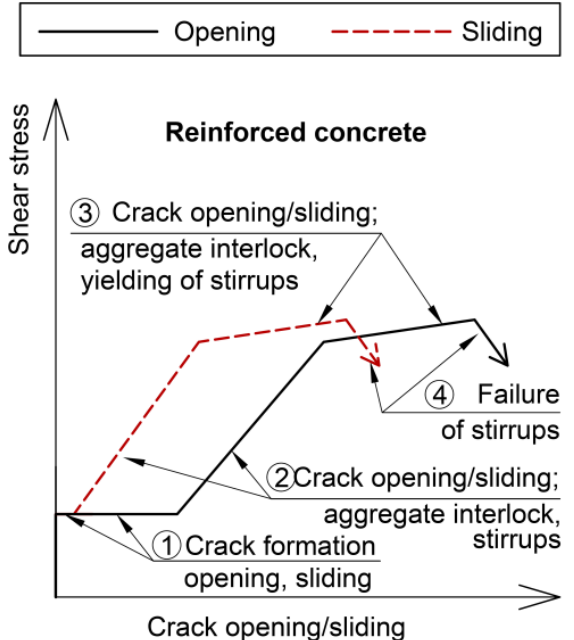

(c)

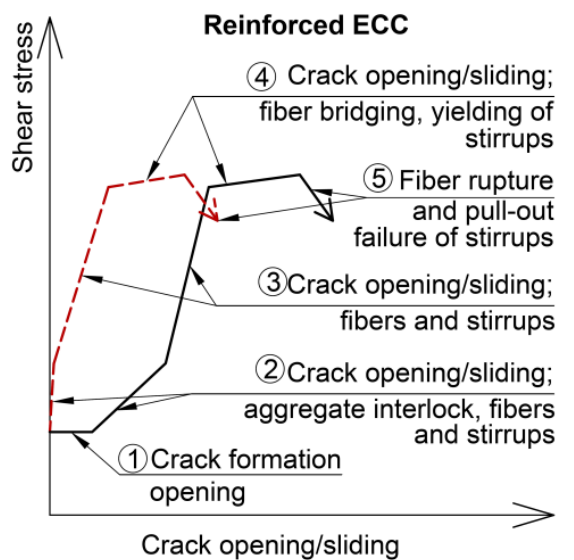

(e)

Figure 13. Shear crack development mechanism of R/C and R/ECC: (a) expected shear crack location; (b) and (c) crack development in R/C; (d) and (e) crack development in R/ECC

For R/ECC, shear load is transferred across the cracks by fiber bridging. The shear crack behavior of R/ECC can be characterized by the following stages as illustrated in Figure $13(d)$ and (e):

1. Initiation of crack opening - brittle crack opening without noticeable sliding. Sliding is resisted by an immediate activation of aggregate interlock, provided by fibers transferring stresses across the crack. 
2. Initiation of crack sliding - crack opening slowly increases with relatively small sliding $(<0.03 \mathrm{~mm})$. Crack opening and sliding are restrained mainly by fiber bridging, aggregate interlock and stirrups. Due to the maximum aggregate size in ECC, aggregate interlock is significantly smaller in ECC than R/C. As a result, once the crack opening exceeds one-half of the maximum aggregate size (i.e., $0.09 \mathrm{~mm}$ ) aggregate interlock terminates. The smaller crack openings are due to the enhanced crack control in tension for ECC, which transfers stresses over the crack with limited crack opening [2]. Evidence indicates that crack deformations increase with shear load more rapidly in this stage than in the following stage. The increased deformation rate may indicate that the traditional reinforcement requires additional deformations to be fully activated on transferring stresses over the crack.

3. Reduced rate of combined crack opening and sliding - crack opening and sliding develop slowly mainly due to fibers and stirrups bridging cracks. The effect of aggregate interlock is reduced due to crack opening exceeding half of the maximum aggregate size (roughly $0.1 \mathrm{~mm})$. For R/ECC beams without transverse reinforcement, crack opening and sliding increase more rapidly. Additional transverse reinforcement inhibits crack opening and sliding due to the increased cross-sectional area of materials bridging the crack. At this stage the stirrups and longitudinal reinforcement (dowel effect) are fully activated.

4. Increased rate of combined crack opening and sliding - crack opening and sliding is resisted mainly by stirrups. Shear stress carried by the stirrups increases and ultimately yielding is reached in the stirrups. At this stage, fibers reach maximum bridging stress and cracking localizes, leading to failure. At the end of this stage additional load causes pullout and/or rupture of the fibers at the weakest crack.

5. Failure - the failure of the specimen is caused by rupture of stirrups in R/ECC and pull-out and failure of fibers in ECC.

Furthermore, during stages 2 and 3 for R/ECC, additional shear cracks may form due to the multiple cracking feature of ECC, temporarily reducing the crack opening rate of the existing shear cracks. The dowel effect by longitudinal reinforcement takes place in the shear stress transfer zone over the crack throughout all stages, but the influence of this mechanism is not included in the schematic description in Figure 13. 


\section{Conclusions and remarks}

The benefits of R/ECC, regards to resisting shear, include improved shear resistance and cracking control. Similar to uni-axial tension, multiple cracking of ECC occurs in shear. The first cracking strength was slightly higher for the R/C used in this study; however, the initial crack opening of the R/C was 10 times larger than that in the R/ECC.

Crack deformations for the R/ECC were between 3 and 5 times smaller than for R/C at similar load levels. The addition of stirrups in R/C controls cracks widths as more stirrups resulted in reduced initial crack opening and total crack deformations (opening and sliding). Initial crack opening was independent of stirrup spacing in the R/ECC beams. The contributions of ECC on shear behavior of R/ECC include:

- Fiber bridging of shear crack, thus increasing the shear capacity;

- Traditional shear reinforcement is activated at smaller individual crack deformations;

- Crack deformations are limited by fiber bridging mechanism and by activating traditional shear reinforcement at smaller crack deformations.

Based on the shear stress-strain responses and DIC measurements of the specimen deformations, a phenomenological descriptions of the shear crack opening, crack sliding and subsequent failure of $\mathrm{R} / \mathrm{C}$ and R/ECC are proposed. For the R/C the shear loads over the shear crack can be transferred only by stirrups, aggregate interlock and fiber dowel effect of longitudinal reinforcement. The crack development mechanism for R/ECC is more complex due to the fiber bridging mechanisms, which induces multiple cracking resulting in smaller crack openings at a given shear stress as well as higher peak shear stress.

The experimental program demonstrated that the use of R/ECC provides improved shear resistance, better control of crack sizes, and a more ductile shear failure than R/C. However, shear stress transfer over the crack via aggregate interlock is significantly reduced in ECC type materials due to the small particle size in the matrix. Additional increases in shear failure ductility of ECC would be possible by using fibers that can resist higher shear deformations and engineering the composite to fail by fiber pullout rather than rupture 


\section{Acknowledgements}

The authors would like to thank Aase and Ejnar Danielsens Fond and Knud Højgaards Fond for cofunding the Ph.D. project of leva Paegle. The work presented herein was a part of her Ph.D. project.

\section{References}

[1] C.V. Li and G. Fischer, "Reinforced ecc - an evolution from materials to structures," FIB Proceedings of the 1st fib Congress, 2002.

[2] V.C. Li, "Engineered Cementitious Composites - Tailored Composites Through Micromechanical Modeling," Fiber Reinforced Concrete: Present and the Future, A. Bentur A. A. Mufti N. Banthia, ed., anadian Society for Civil Engineering, 1998, pp. 64-97.

[3] L.H. Larusson, G. Fischer, and J. Jonsson, "Mechanical interaction of Engineered Cementitious Composite (ECC) reinforced with Fiber Reinforced Polymer (FRP) rebar in tensile loading," Advances in Cement-Based Materials - Proceedings of the International Conference on Advanced Concrete Materials, CRC Press, 2010, pp. 83-90.

[4] Y. Hiraishi, T. Honma, M. Hakoyama, and S. Miyazato, "Steel Corrosion at Bending Cracks in Ductile Fiber Reinforced Cementitious Composites," 28th Conference on Our World in Concrete \& Structures, 2003, pp. 333-340.

[5] S. Miyazato and Y. Hiraishi, "Transport properties and steel corrosion in Ductile Fiber Reinforced Cement Composites," 11th International Conference on Fracture 2005, ICF11, vol. 2, 2005, pp. 1500-1505.

[6] G. Fischer and V.C. Li, "Influence of matrix ductility on tension-stiffening behavior of steel reinforced engineered cementitious composites (ECC)," ACl Structural Journal, vol. 99, 2002, pp. 104-111.

[7] L.H. Lárusson, G. Fischer, and J. Jönsson, "Mechanical interaction between concrete and structural reinforcement in the tension stiffening process," High Performance Fiber Reinforced Cement Composites 6, Springer, 2011.

[8] E.C. Bentz, F.J. Vecchio, and M.R. Collins, "Simplified modified compression field theory for calculating shear strength of reinforced concrete elements," ACI Structural Journal, vol. 103, 2006, pp. 614-624.

[9] F. Majdzadeh, S.M. Soleimani, and N. Banthia, "Shear strength of reinforced concrete beams with a fiber concrete matrix," Canadian Journal of Civil Engineering, vol. 33, 2006, pp. 726-734.

[10] S. Altoubat, A. Yazdanbakhsh, and K.-A. Rieder, "Shear behavior of macro-synthetic fiberreinforced concrete beams without stirrups," ACI Materials Journal, vol. 106, 2009, pp. 381-389.

[11] K.K. Choi, J.K. Wight, and H.G. Park, "Shear strength of steel fiber-reinforced concrete beams without web reinforcement," ACI Structural Journal, vol. 104, 2007, pp. 12-21.

[12] M. Imam, L. Vandewalle, F. Mortelmans, and D. Van Gemert, "Shear domain of fibre-reinforced high-strength concrete beams," Engineering Structures, vol. 19, 1997, pp. 738-747. 
[13] T. Kanda, S. Watanabe, and V.C. Li, "Application of pseudo strain hardening cementitious composites to shear resistant structural elements," Fracture Mechanics of Concrete Structures Proceedings FRAMCOS-3 AEDIFICATIO Publishers, D-79104 Freiburg, Germany, 1998.

[14] V.C. Li, R. Ward, and A.M. Hamza, "Steel and synthetic fibers as shear reinforcement," $A C l$ Materials Journal, vol. 89, 1992, pp. 499-508.

[15] R. Narayanan and I.Y.S. Darwish, "Use of steel fibers as shear reinforcement.," ACI Structural Journal (American Concrete Institute), vol. 84, 1987, pp. 216-227.

[16] G.J. Parra-Montesinos, "Shear Strength of Beams with Deformed Steel Fibers - Evaluating an alternative to minimum transverse reinforcement," Concrete International - the Magazine of the American Concrete Institute, vol. 28, 2006, p. 57.

[17] $\mathrm{ACl}-318, \mathrm{ACl} 318-08$ building code requirements for structural concrete and commentary, $\mathrm{ACl}$ Committee 318, 2008.

[18] ACl-318, ACl 318-08 building code requirements for structural concrete and commentary, $\mathrm{ACl}$ Committee 318, 2014.

[19] H.H. Dinh, H.H. Dinh, G.J. Parra-Montesinos, and J.K. Wight, "Shear strength model for steel fiber reinforced concrete beams without stirrup reinforcement," Journal of Structural Engineering, vol. 137, 2011, pp. 1039-1051.

[20] H.H. Dinh, G.J. Parra-Montesinos, and J.K. Wight, "Shear behavior of steel fiber-reinforced concrete beams without stirrup reinforcement," ACI Structural Journal, vol. 107, 2010, pp. 597606.

[21] SP52-104, Building Norms and Rules SP 52-104-2009. Steel fiber reinforced structures, Moscow, 2010.

[22] fib, Model Code for Concrete Structures 2010 - Final draft, fib Bulletin No. 65 and 66, Ernst \& Sohn, 2012.

[23] R.T.C. 162-TDF, "RILEM T.C. 162-TDF: Test and design methods for steel fibre reinforced concrete - sigma-epsilon-design method - Final recommendations," Materials and Structures, vol. 36, 2003, pp. 560-567.

[24] F. Minelli, "Plain and Fiber Reinforced Concrete Beams under Shear Loading: Structural Behavior and Design Aspects," Ph.D. thesis, Department of Civil Engineering, University of Brescia, 2005.

[25] F. Minelli and G.A. Plizzari, "On the Effectiveness of Steel Fibers as Shear Reinforcement," Aci Structural Journal, Aci Struct. J, Aci Struc J, Aci Struct J, vol. 110, 2013, pp. 379-389.

[26] S.J. Foster, Y.L. Voo, and K.T. Chong, "FE Analysis of Steel Fiber Reinforced Concrete Beams Failing in Shear: Variable Engagement Model," ACI SP-237 Finite Element Analysis of Reinforced Concrete Structures, 2006.

[27] JSCE, Recommendations for design and construction of High Performance Fiber Reinforced Cement Composites with fine multiple cracks, 2008.

[28] T. Kanakubo, K. Shimizu, S. Nagai, and T. Kanda, "Shear transmission on crack surface of ECC," Proceedings of FraMCos-7, Jeju (Korea), et al. B. H. Oh, ed., 2010, pp. 1623-1630. 
[29] K. Shimizu, T. Kanakubo, T. Kanda, and S. Nagai, "Shear Behavior of PVA-ECC Beams," International RILEM Workshop on High Performance Fiber Reinforced Cementitious Composites in Structural Applications, 2006.

[30] S. Nagai, Kanda, Tetushi, M. Maruta, and T. Miyashita, "Shear capacity of ductile wall with high performance fiber reinforced cement composite," Proceedings of the 1st fib Congress, 2002.

[31] P. Kabele, "Fracture Behavior of Shear-Critical Reinforced HFRCC Members, Proceedings on the 49th International RILEM Workshop on High Performance Fiber Reinforced Cementitious Composites in Structural Applications, Honolulu, USA:383-392.," Proceedings on the International RILEM Workshop on High Performance Fiber Reinforced Cementitious Composites (HPFRCC) in Structural Applications, V.C. G. Li. Fischer, ed., Honolulu, Hawaii, USA: 2005, pp. 383-392.

[32] S.A. Ashour, G.S. Hasanain, and F.F. Wafa, "Shear behavior of high-strength fiber reinforced concrete beams," ACl Structural Journal, vol. 89, 1992, pp. 176-184.

[33] Y.-K. Kwak, M.O. Eberhard, W.-S. Kim, and J. Kim, "Shear strength of steel fiber-reinforced concrete beams without stirrups," ACI Structural Journal, vol. 99, 2002, pp. 530-538.

[34] M. Mansur, K. Ong, and P. Paramasivam, "Shear Strength of Fibrous Concrete Beams Without Stirrups," Journal of Structural Engineering, vol. 112, 1986, pp. 2066-2079.

[35] A. Sharma, "Shear-strength of steel fiber reinforced-concrete beams," Journal of The American Concrete Institute, vol. 83, 1986, pp. 624-628.

[36] F.J. Vecchio and M.P. Collins, "Modified compression-field theory for reinforced concrete elements subjected to shear.," Journal of The American Concrete Institute, vol. 83, 1986, pp. 219-231.

[37] Q. Shang and G.P.A.G. Van Zijl, "Characterising the shear behaviour of strainhardening fibrereinforced cement-based composites," Journal of the South African Institution of Civil Engineering, vol. 49, 2007, pp. 16-23.

[38] V.C. Li, D.K. Mishra, A.E. Naaman, and Y. James K. LaFave James M. Wu Hwai-Chung Inada Wight, "On the shear behavior of engineered cementitious composites," Advanced Cement Based Materials, vol. 1, 1994, pp. 142-149.

[39] GOM, “GOM Optical Measuring Techniques, 'Aramis v5.4 User Manual', GOM mbH,” 2005.

[40] B.J. Pease, H. M.R. Stang Geiker, and W.J. Weiss, "Photogrammetric Assessment of Flexure Induced Cracking of Reinforced Concrete Beams under Service Loads," Proceedings of the 2nd International RILEM Symposium, Advances in Concrete through Science and Engineering, Québec City, Canada, 2006. 


\section{List of Tables}

Table 1. Properties of PVA fibers

Table 2. Mixture proportions

Table 3. Reinforcement detailing in the test specimens

Table 4. Test results from shear beam tests

Table 5. Values of crack opening and sliding

\section{List of Figures}

Figure 1. Tensile properties of ECC

Figure 2. Tensile test: (a) specimen geometry; (b) test setup

Figure 3. Shear beam test setup configuration (a), shear force distribution (b), moment distribution (c)

Figure 4. Test set-up and area of interest

Figure 5. Shear stress - strain relationship for (a) R/C and (b) R/ECC. Deformations captured using DIC.

Figure 6. Contribution of concrete/ECC, transverse reinforcement and composite action on shear capacity

Figure 7. Illustration of crack deformations: (a) schematic definition of crack opening and sliding; (b) illustration from DIC software

Figure 8. Crack formation in a) R/C and b) R/ECC beam specimens at different load stages

Figure 9. Crack distribution of a) R/C and b) R/ECC beams at $100 \%$ of peak strength for increasing amounts of shear reinforcement (decreasing spacing)

Figure 10. Shear cracks in beam at peak shear stress: a) R/C and b) R/ECC

Figure 11. Zoom in highlighted region in Figure 10: a) R/C and b) R/ECC

Figure 12. Characteristic shear stress - crack opening and sliding deformation relationship for: (a) R/C0; (b) R/ECC-0; (c) R/C-d; (d) R/ECC-d; (e) R/C-1/2d; (f) R/ECC-1/2d; (g) R/C-1/4d and (h) R/ECC-1/4d beams

Figure 13. Shear crack development mechanism of R/C and R/ECC: (a) expected shear crack location; (b) and (c) crack development in R/C; (d) and (e) crack development in R/ECC 